\title{
STC2 overexpression mediated by $H M G A 2$ is a biomarker for aggressiveness of high-grade serous ovarian cancer
}

\author{
JINGJING WU ${ }^{1,2}$, MAODE LAI $^{1}$, CHANGSHUN SHAO ${ }^{3}$, JIAN WANG $^{4}$ and JIAN-JUN WEI ${ }^{2}$ \\ ${ }^{1}$ Department of Pathology, Zhejiang University School of Medicine, Hangzhou, Zhejiang 310058, P.R. China; \\ ${ }^{2}$ Department of Pathology, Northwestern University School of Medicine, Chicago, IL 60611, USA; \\ ${ }^{3}$ Department of Genetics and the Human Genetics Institute of New Jersey, Rutgers University, \\ Piscataway, NJ 08854, USA; ${ }^{4}$ Department of Surgical Oncology, Second Affiliated Hospital, \\ Zhejiang University School of Medicine, Hangzhou, Zhejiang 310009, P.R. China
}

Received March 25, 2015; Accepted June 17, 2015

DOI: 10.3892/or.2015.4120

\begin{abstract}
High-grade serous cancer (HGSC) is a lethal form of ovarian cancer due to invasion and early metastasis. Gain of epithelial-mesenchymal transition (EMT) contributes to the aggressiveness of HGSC. High-mobility gene group A2 (HMGA2), an architectural transcription factor, plays a major role in HGSC through the regulation of EMT gene expression. Based on the gene profiling analysis, we found that the potent EMT gene, stanniocalcin 2 (STC2), was highly correlated with $H M G A 2$ expression. In the present study, we demonstrated that $S T C 2$ was directly regulated by $H M G A 2$ at the transcriptional level. Overexpressing STC2 in vitro directly enhanced cell migration and invasion. To investigate the correlation of STC2 and HMGA2 expression and the potential biomarker for ovarian cancer, three independent large cohorts of ovarian cancer (cohort $1=278$, cohort $2=150$ and cohort $3=95$ cases) were examined in the present study. The results showed that the expression of HMGA2 and STC2 was positively correlated. Furthermore, STC2 expression was significantly associated with tumor grade and histotype. HGSC had significantly higher levels of STC2 expression and was inversely correlated with patient survival. These findings suggested that STC2 is an important new biomarker that can be used for HGSC.
\end{abstract}

\section{Introduction}

Ovarian cancer is a lethal disease characterized by early metastasis. According to the American Cancer Society, 21,980 women

Correspondence to: Dr Jian-Jun Wei, Department of Pathology, Northwestern University School of Medicine, Feinberg 7-334, 251 East Huron Street, Chicago, IL 60611, USA

E-mail: jianjun-wei@northwestern.edu

Dr Jian Wang, Department of Surgical Oncology, Second Affiliated Hospital, Zhejiang University School of Medicine, 88 Jiefang Road, Hangzhou, Zhejiang 310009, P.R. China

E-mail: wangjian519@zju.edu.cn

Key words: HMGA2, STC2, ovarian cancer developed ovarian cancer and 14,270 women succumbed to this disease in 2014 in the US (1). Ovarian cancer is histologically heterogeneous, and $50-70 \%$ of ovarian cancers are high-grade serous ovarian carcinoma (HGSC). Most patients (up to $70 \%)$ are diagnosed at an advanced stage. Despite advances in medical research, the survival rate of ovarian cancer has remained unchanged in the past 50 years $(2,3)$. Thus, it is crucial to identify a potential therapeutic target for HGSC.

High-mobility gene group A2 (HMGA2), as an oncofetal protein, participates in ovarian carcinogenesis $(4,5)$. HMGA2 is overexpressed in $>70 \%$ of early serous tubal intraepithelial carcinoma (STIC) and late stages of human HGSC (6), as well as in early ovarian cancer in a mouse model (4). HMGA2 overexpression resulted in malignant tumor transformation in ovarian epithelial cells (7). Silencing HMGA2 in ovarian cancer cells inhibited tumor growth in vivo (8). The oncogenic properties of $H M G A 2$ in promoting the aggressiveness of malignancy were mainly attributed to its regulation of epithelial-mesenchymal transition (EMT) (9-11). A global gene profiling analysis revealed that $H M G A 2$ overexpression upregulated stanniocalcin 2 (STC2) (7).

Stanniocalcin (STC) is a glycoprotein hormone originally found to be produced by the corpuscles of Stannous in bony fish. Its main function is to regulate calcium and phosphate homeostasis (12). This hormone has two members: The STC1 gene, mapped at chromosome $8 \mathrm{p} 11$, whose protein contains 247 amino acids and the STC 2 gene, located at 5q35, whose protein consists of 302 amino acids and has $34 \%$ homology to STC1 (13). STC1 was reported to be a Ras-induced gene leading to the aggressive tumor growth of ovarian cancer in vitro and in vivo (14). STC2 overexpression was found to be associated with cancer progression and worse clinical outcome (15-18). Previous findings showed that STC2 was regulated by HIF-1 under hypoxic conditions and the induction of STC2 stimulated cell proliferation and promoted EMT formation in ovarian cancer (19). The exact regulation mechanism of STC2 in cancer, in particular in ovarian cancer remains unknown.

In the present study, we characterized the oncogenic properties of $S T C 2$ in ovarian cancer cells and investigated HMGA2-mediated STC2 upregulation. We found that STC2 was directly upregulated by $H M G A 2$ at the transcriptional 
level. STC2 promoted cell migration and invasion in vitro. Of note, studies of several large cohorts focusing on human ovarian cancer populations revealed that the expression of $H M G A 2$ and STC2 was positively correlated and associated with tumor grades and histologic subtypes. High STC2 was associated with poor clinical outcome of ovarian cancer.

\section{Materials and methods}

Patients and tissue samples. Three ovarian cancer populations were used in the present study. The training set consisted of 278 ovarian cancer cases was purchased from US Biomax Inc. (Rockville, MD, USA). The validation set consisted of 150 ovarian cancer cases and was purchased from Super BioTek (Shanghai, China). The clinical biodemography, pathological features and clinical outcomes of patients were collected by retrospective chart review (Table I). The third cohort of 95 patients with ovarian cancer was obtained from the Northwestern Memorial Hospital between 2002 and 2007. This cohort had follow-up information and the information was previously reported (20). Ethics approval for the study was obtained from the Institutional Review Board.

Stable overexpression of STC2 in T29 cells. T29 were plated in 6-well plates in antibiotic-free medium. When the cells reached $70-80 \%$ confluence, each well was transfected with a mixture containing either $4 \mu \mathrm{g}$ of pCMV6-STC2 or control pCMV6 and $10 \mu \mathrm{l}$ of Lipofectamine 2000. Seventy-two hours after transfection, the cells were selected for 20-30 days in the

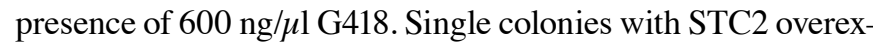
pression were selected and confirmed by western blot analysis.

Stable knockdown of STC2 in Caov-3 cells. STC2 shRNA (pGPU6/GFP/Neo-shRNA-1604 with target sequence GGGCAAGTCATTCATCAAAGA) and STC2 control (the scrambled shRNA construct pGPU6/GFP/Neo-shNC) plasmids were transfected into cells using Lipofectamine 2000 as previously described (7). Single colonies with STC2 knockdown were selected and confirmed by western blot analysis.

Wound-healing assay. The cells (9x10 $)$ were seeded in 6-well plates and allowed to reach confluence overnight in culture medium. A linear scratch was created using a sterile pipette tip. The media were then changed to remove any detached cells and the scratched areas were photographed under an inverted microscope at indicated time points. At least three fields along each scratch were analyzed and the experiment was performed in triplicate.

Transwell migration and Matrigel invasion assays. Cells (1x10 $/$ well) were suspended in $200 \mu \mathrm{l}$ of serum-free medium and then seeded on the upper side of a 24-well Transwell migration chamber (Corning Inc., Corning, NY, USA). After 48 h, the cells retained on the upside of the membrane were removed by cotton swab. The cells that migrated onto the bottom side were fixed by $10 \%$ formalin, stained by $0.1 \%$ crystal violet and observed under microscope at a magnification of $x 100$. The Matrigel invasion assay was similar to the Transwell migration assay, except that the upside of the membrane was coated with the Matrigel.
Table I. Characteristics of the training $(n=278)$ and validation cohort $(n=150)$.

\begin{tabular}{|c|c|c|}
\hline Characteristics & $\begin{array}{l}\text { Training cohort } \\
\qquad(\%)\end{array}$ & $\begin{array}{c}\text { Validation cohort } \\
(\%)\end{array}$ \\
\hline \multicolumn{3}{|l|}{ Age (years) } \\
\hline$\leq 50$ & $160(57.6)$ & $69(46.0)$ \\
\hline$>50$ & $118(42.4)$ & $81(54.0)$ \\
\hline \multicolumn{3}{|l|}{ T stage } \\
\hline $\mathrm{T} 1$ & $194(69.8)$ & $72(48.0)$ \\
\hline $\mathrm{T} 2$ & $39(14.0)$ & $52(34.7)$ \\
\hline $\mathrm{T} 3$ & $33(11.9)$ & $26(17.3)$ \\
\hline $\mathrm{T} 4$ & $12(4.3)$ & $0(0.0)$ \\
\hline \multicolumn{3}{|l|}{ Grading } \\
\hline 1 & $75(27.0)$ & $44(29.3)$ \\
\hline 2 & $79(28.4)$ & $50(33.3)$ \\
\hline 3 & $124(44.6)$ & $56(37.3)$ \\
\hline \multicolumn{3}{|l|}{ Node metastasis } \\
\hline Absent & $243(87.4)$ & $143(95.3)$ \\
\hline Present & 35 (12.6) & $7(4.7)$ \\
\hline \multicolumn{3}{|c|}{ Distant metastasis } \\
\hline Absent & $266(95.7)$ & $135(90.0)$ \\
\hline Present & $12(4.3)$ & $15(10.0)$ \\
\hline \multicolumn{3}{|l|}{ Histotype } \\
\hline Serous & $222(79.9)$ & $108(72.0)$ \\
\hline Mucinous & $56(20.1)$ & $42(28.0)$ \\
\hline Total & $278(100)$ & $150(100)$ \\
\hline
\end{tabular}

Immunohistochemical analysis. After formalin-fixed and paraffin-embedded tissue samples were treated with xylene and ethanol, antigen retrieval was performed in 11 of citrate buffer $(0.01 \mathrm{~mol} / 1, \mathrm{pH} 6.0)$ at $95^{\circ} \mathrm{C}$ for $10 \mathrm{~min}$. Endogenous peroxidase activity was inactivated with $3 \% \mathrm{H}_{2} \mathrm{O}_{2}$ for $10 \mathrm{~min}$ at room temperature (RT) and slides were blocked in $10 \%$ goat serum at RT for $30 \mathrm{~min}$. The sections were then incubated with rabbit polyclonal anti-HMGA2 (1:100; Bio-Check, Inc. (Foster City, CA, USA) or rabbit polyclonal anti-STC2 (1:100; Abcam, Cambridge, MA, USA) at $4^{\circ} \mathrm{C}$ overnight. Subsequently, the sections were treated with secondary antibody at RT for $1 \mathrm{~h}$. The slides were incubated with diaminobenzidine (DAB) and counterstained with hematoxylin. Immunohistochemical staining scoring was semi-quantitatively evaluated by staining intensity and the percentage of positive cells. The percentage positivity was graded as $0(<5 \%), 1(5-25 \%), 2(25-50 \%), 3(51-75 \%)$, or $4(>75 \%)$. The staining intensity was graded as 0 (no staining), 1 (weak staining), 2 (moderate staining) or 3 (strong staining). The two grades were added together to yield the immunoreactive score (IRS). Cases with discrepancies in IRS were discussed with other pathologists until consensus was reached. Evaluation of immunohistochemical staining was carried out by two pathologists (J.-J. Wei and M. Lai) blinded to the clinicopathological characteristics. 
Table II. Primers for construction of STC2 promoter in pGL3 luciferase plasmid.

\begin{tabular}{llc}
\hline Primer site & \multicolumn{1}{c}{ Sequences 5'-3' } & Product (bp) \\
\hline-290 to +43 & F: 5'-CCGCTCGAGACTCCTTCATTCAAGTGACA-3' & 334 \\
& R: 5'-CCCAAGCTTACCAAAGCCAGGGTCATG-3' \\
-647 to +43 & F: 5'-CCGCTCGAGAACTTTCCCAACCCGATGT-3' & 691 \\
$-1,313$ to +43 & R: 5'-CCCAAGCTTACCAAAGCCAGGGTCATG-3' & \\
& F: 5'-CCGCTCGAGAACTTTCTCCTTCCCTCCA-3' & 1,357 \\
$-1,313$ to -620 & R: 5'-CCCAAGCTTACCAAAGCCAGGGTCATG-3' & 694 \\
& F: 5'-CCGCTCGAGAACTTTCTCCTTCCCTCCA-3' & \\
\hline
\end{tabular}

STC2, stanniocalcin 2; F, forward; R, reverse.

Western blotting. Equal amounts $(25 \mu \mathrm{g})$ of total proteins were resolved by $12 \%$ SDS-PAGE and transferred to polyvinylidene fluoride (PVDF) membranes. The membranes were blocked with 5\% non-fat milk for $1 \mathrm{~h}$ at RT and incubated with primary antibodies at $4{ }^{\circ} \mathrm{C}$ overnight, including rabbit polyclonal antiSTC2 (1:200; Abcam) and mouse monoclonal anti- $\beta$-actin (1:1,000; Sigma, St. Louis, MO, USA). The secondary antibody was then detected by an enhanced chemiluminescence kit (Perkin-Elmer, Waltham, MA, USA).

Luciferase assay. The upstream regions of human STC2 from $-290 /+43,-647 /+43,-1,313 /+43,-1,313 /-620$ were generated by PCR (Table II) and cloned into the pGL3-basic plasmid. The $293 \mathrm{~T}$ cells were seeded in 24-well plates at densities of $7 \times 10^{4} /$ well. After $24 \mathrm{~h}, 0.1 \mu \mathrm{g}$ of pRL-TK, $0.5 \mu \mathrm{g}$ of pGL3-STC2 and the indicated amounts $(0,0.2,0.4$ and $0.8 \mu \mathrm{g})$ of pcDNA3.1-HMGA2, along with varied amounts $(0.8,0.6$, 0.4 and $0 \mu \mathrm{g}$ ) of blank pcDNA3.1 plasmid were transfected into $293 \mathrm{~T}$ cells by Lipofectamine 2000. Forty-eight hours after transfection, the firefly luciferase activity was measured with the Dual-Luciferase Reporter Assay System (Promega, Madison, WI, USA), and results were normalized by Renilla luciferase activity. The experiments were repeated at least three times with three replicates per sample.

Statistical analysis. The associations between expression status and clinicopathological characteristics were assessed using the $\chi^{2}$ test. Overall survival curves were calculated for the expression groups using the Kaplan-Meier method. RNA and protein expression levels were presented as means \pm standard deviation from at least three independent experiments. Data were analyzed by the Student's t-test in two groups and one-way ANOVA in multiple groups. SPSS 17.0 software was used for statistical analysis. $\mathrm{P}<0.05$ was considered to indicate a statistically significant result.

\section{Results}

Overexpression of STC2 promotes cell migration and invasion in ovarian surface epithelial cells in vitro. To examine the roles of $S T C 2$ in cell mobility, a stable $S T C 2$ overexpression was established in an ovarian T29 surface epithelial cell line (T29-
STC2) (Fig. 1A). Cells with a vector control (T29-pCMV6) were used. Introduction of $S T C 2$ overexpression enhanced cell metastasis and invasion in vitro. The wound-healing assay revealed that the closure rates of T29-STC2 at 12,36 and $48 \mathrm{~h}$ $(36.77 \pm 1.55,82.59 \pm 1.50$ and $97.33 \pm 1.15 \%)$ were significantly higher than those of T29-pCMV6 $(25.69 \pm 2.22,61.50 \pm 1.10$ and $81.45 \pm 1.13 \%$; $\mathrm{P}<0.01$, Fig. 1B). The Transwell chamber assay indicated that migration of the T29-STC2 cells $(301.33 \pm 9.29)$ was significantly higher than that of T29-pCMV6 (174.67 \pm 6.03 , $\mathrm{P}<0.001$, Fig. 1C) at $24 \mathrm{~h}$. In the Matrigel invasion assay, we also observed a significant induction of the invasive potential of T29-STC2 $(232.67 \pm 10.69)$ compared to that of the control (112.33 $\pm 7.57, \mathrm{P}<0.001$, Fig. 1D). These results demonstrated that $S T C 2$ overexpression promoted the migration and invasion of ovarian surface epithelial cells in vitro.

Knockdown of STC2 inhibits cell migration and invasion in ovarian cancer cells in vitro. To investigate whether blocking STC2 restored or reduced the cell aggressiveness, we used the ovarian cancer cell line, Caov-3. Caov-3 exhibited abundant endogenous $S T C 2$ expression. A stable knockdown cell (Caov-3-sh-STC2) and scrambled control cell (Caov-3-pGPU6) were prepared (Fig. 2A).

The wound closure rates of Caov-3-sh-STC2 at 12, 24 and $48 \mathrm{~h}(37.35 \pm 2.50,47.79 \pm 2.20$ and $62.48 \pm 4.89 \%)$ were significantly lower than those of Caov-3-pGPU6 $(56.28 \pm 3.69$, $74.33 \pm 4.91$ and $87.10 \pm 4.35 \%, P<0.01$, Fig. $2 B$ ), indicating that the downregulation of STC2 reduced the locomotion of the cancer cells. Similarly, the number of cells migrating through the Transwell membrane was significantly reduced in Caov-3sh-STC2 cells (83 \pm 4$)$, compared with the Caov-3-pGPU6 cells $(151 \pm 5.57, \mathrm{P}<0.001$, Fig. $2 \mathrm{C})$. The Matrigel invasion assay revealed that blocking STC2 expression inhibited the invasiveness of Caov- 3 cells $(41.33 \pm 3.21$ for Caov-3-sh-STC2 cells vs. 96.33 \pm 6.02 for Caov-3-pGPU6 cells, $\mathrm{P}<0.001$, Fig. 2D). These results indicated that knockdown of STC2 inhibited cell migration and invasion in ovarian cancer in vitro.

STC2 is regulated by HMGA2 at transcription levels. Gene profiling analysis revealed that ovarian epithelial cells with HMGA2 overexpression enhanced STC2 expression (7). 


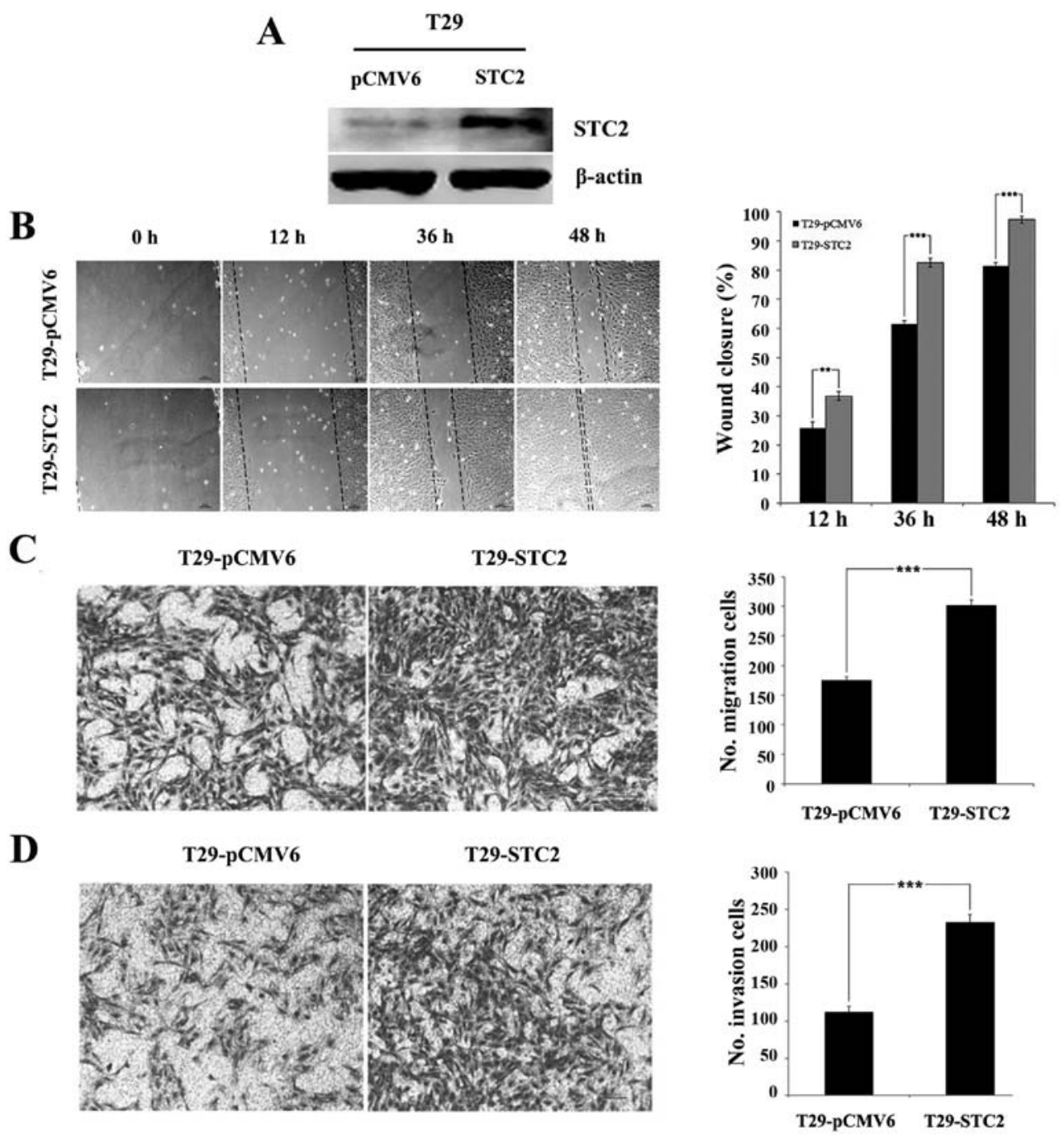

Figure 1. STC2 overexpression significantly promotes cell migration and invasion in T29 cells. (A) STC2 protein levels in T29-pCMV6 and T29-STC2 stable cell lines are shown by western blot analysis. (B) Representative images of T29-pCMV6 and T29-STC2 cells at 0, 12, 36 and $48 \mathrm{~h}$ post-scratch at x100 magnification (left panel). The bar graph shows the mean \pm SD (percent of wound closure) of three idnependent experiments with five fields measured per experiment (right panel). (C) In the Transwell migration and (D) Matrigel invasion assays, images of T29-pCMV6 and T29-STC2 cells that had (C) migrated or (D) invaded to the lower chamber were captured at x100 magnification (left panel). The bar graph shows the quantification of the cell migration (right panel). ${ }^{* *} \mathrm{P}<0.01 ;{ }^{* * *} \mathrm{P}<0.001$. STC2, stanniocalcin 2.

To determine whether $H M G A 2$ directly regulated $S T C 2$ expression, we examined $H M G A 2$ and $S T C 2$ expression at transcription levels using RT-PCR in 11 randomly selected HGSC samples. As shown in Fig. 3A, there was a correlation between $H M G A 2$ and $S T C 2$ expression. We then investigated whether the increased STC2 expression was directly regulated by $H M G A 2$ at the transcription level. The sequence analysis revealed multiple $H M G A 2$ AT binding domains (21) along the 1,200 bp region upstream from the 5 transcription start site of STC2. To define the genomic regions that were possibly regulated by $H M G A 2$, we prepared several luciferase reporter constructs representing different parts of the $S T C 2$ promoter (Fig. 3B). The genomic region immediately adjacent to the $S T C 2$ transcription start site, up to $-600 \mathrm{bp}$, conferred a significant increase in luciferase expression when co-transfected with the HMGA2 expression vector (Fig. 3B). Elevation in luciferase activity in response to $H M G A 2$ co-transfection was dose-dependent (Fig. 3B). By contrast, the upstream sequence beyond this region showed minimal activity in driving luciferase expression, indicating that the $H M G A 2$ regulatory region was mostly confined to the +1 to $-600 \mathrm{bp}$ promoter region of $S T C 2$. The findings suggested that $H M G A 2$-induced $S T C 2$ upregulation was likely mediated by transcription regulation.

STC2 expression is positively correlated with HMGA2 expression in epithelial ovarian cancer. The abovementioned results indicated that $S T C 2$ was associated with aggressive tumor growth and was regulated by HMGA2. To examine whether STC2 expression was correlated with HMGA2 expression at the protein level in epithelial ovarian cancer (EOC), immunohistochemical analysis (Fig. 3C) was employed for measurement of the protein expressions in two cohorts of the EOC cases. The results showed a moderate correlation between HMGA2 and STC2 expression in the training cohort $(\mathrm{R}=0.544, \mathrm{P}<0.001$, Fig. 3D) and validation cohort $(\mathrm{R}=0.286$, 
A

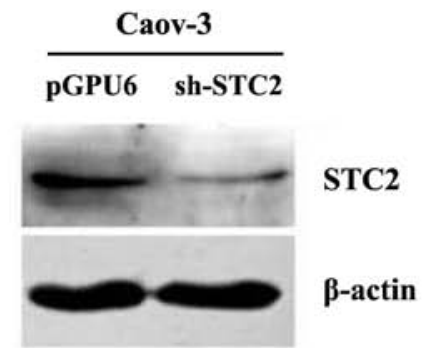

B
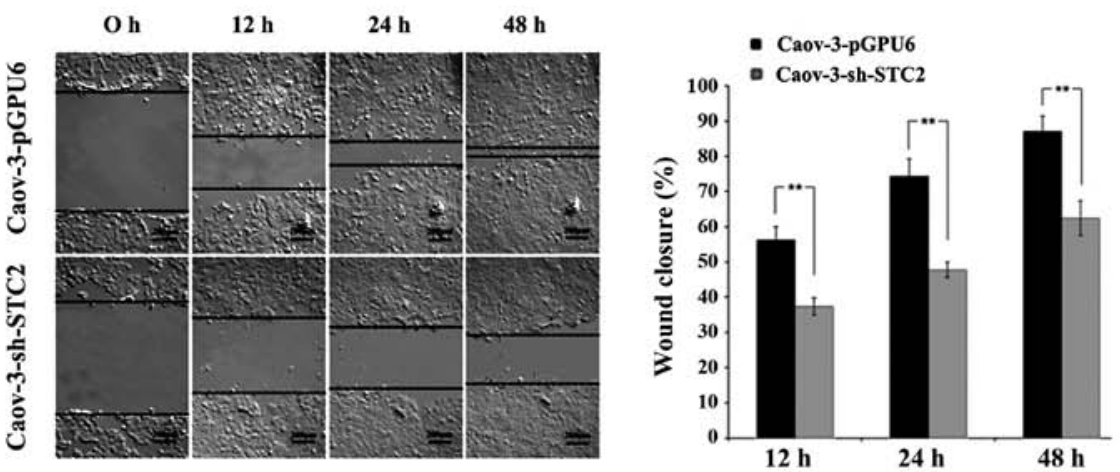

C
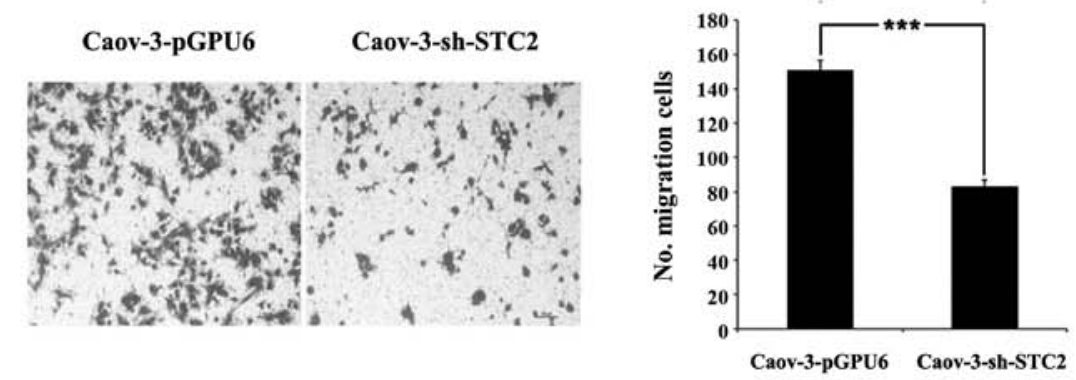

D

Caov-3-pGPU6

Caov-3-sh-STC2
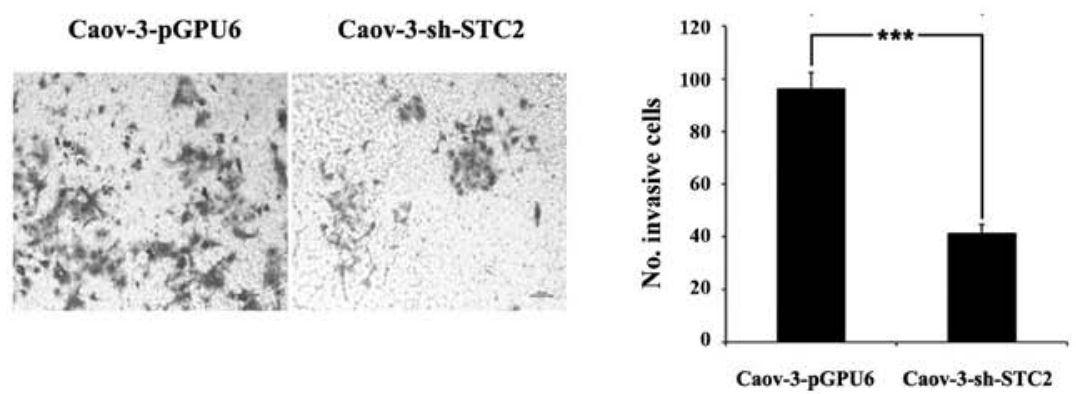

Figure 2. STC2 knockdown significantly inhibits cell migration and invasion in Caov-3 cells. (A) Stable knockdown of STC2 in Caov-3-sh-STC2 cells was confirmed by western blot analysis. (B) Images of Caov-3-pGPU6 and Caov-3-sh-STC2 cells at 0,12, 24 and 48 h post-scratch at x100 magnification (left panel). Wound closure was quantified and the values are shown as mean $\pm \mathrm{SD}$ of three independent experiments with five fields measured per experiment (right panel). (C) In the Transwell migration and (D) Matrigel invasion assays, representative images of Caov-3-pGPU6 and Caov-3-sh-STC2 cells that had migrated to the lower chamber were captured at $\times 100$ magnification (left panel). The number of (C) migrated or (D) invasive cells were quantified (right panel). ${ }^{* *} \mathrm{P}<0.01$; ${ }^{* * * *} \mathrm{P}<0.001$. STC2, stanniocalcin 2 .

$\mathrm{P}<0.001$, Fig. 3E). These findings suggested that STC2 expression was mainly regulated by HMGA2 but may also be regulated by other genes or pathways.

Expression of STC2 correlates with tumor grade and histologic subtype. The clinicopathological characteristics of the training and validation cohort are shown in Table I. As shown in Tables III and IV and Fig. 4, strong immunoreactivity for HMGA2 and STC2 staining were closely associated with tumor grade. In the training cohort, the patients with higher grade had a significantly higher HMGA2 $(\mathrm{P}<0.001$; Table III, Fig. 4A and C). A similar trend was observed in STC2 expression $(\mathrm{P}<0.001$; Table III, Fig. 4B and $\mathrm{D})$. The validation cohort results were consistent with those of the training cohort. Increasing tumor grade showed a statistically positive association with a higher expression of HMGA2 $(\mathrm{P}=0.003$; Table IV, Fig. 4A and C) and STC2 (P=0.013; Table IV, Fig. 4B and D).

A strong correlation between histologic subtypes and the levels of HMGA2 and STC2 expression was identified. A higher 
A

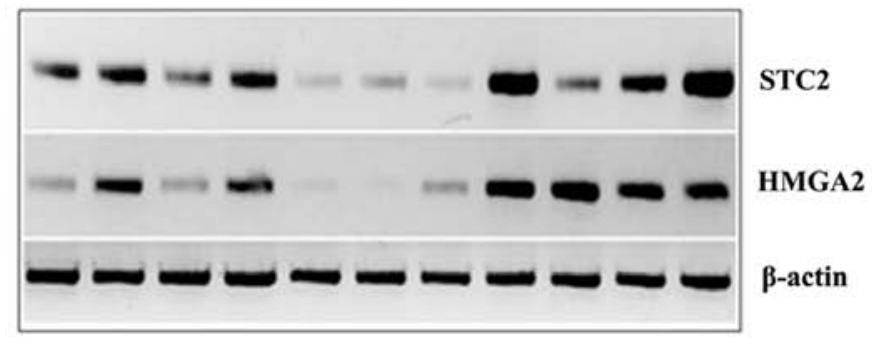

C HMGA2
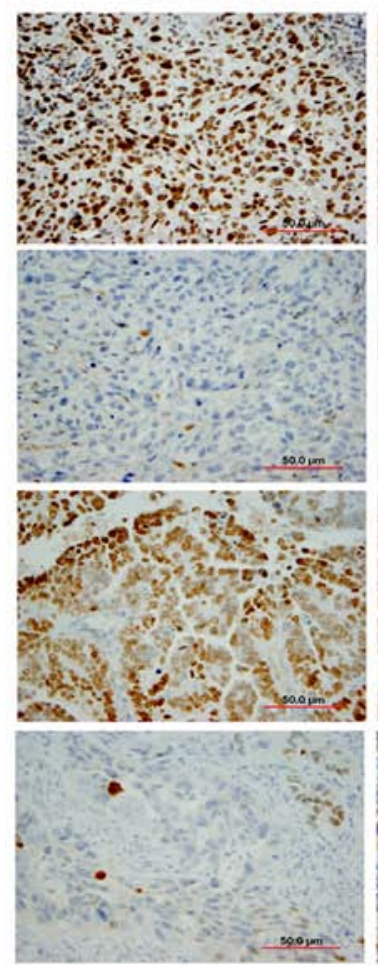

STC2
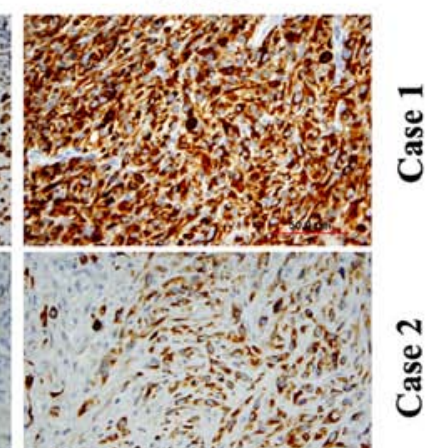

B

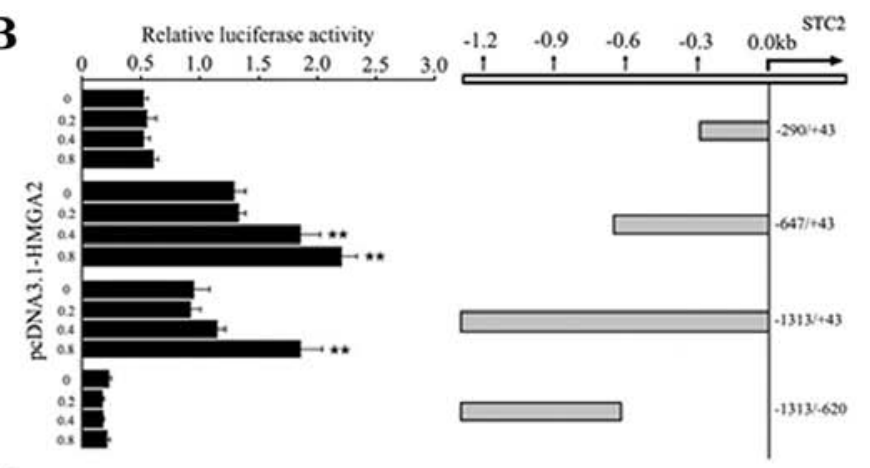

D

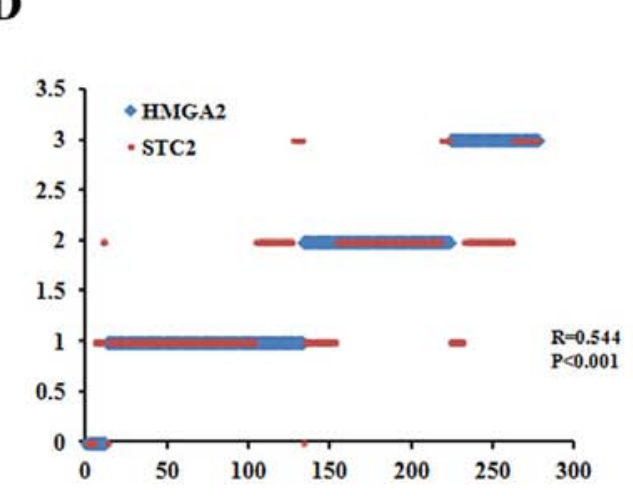

E
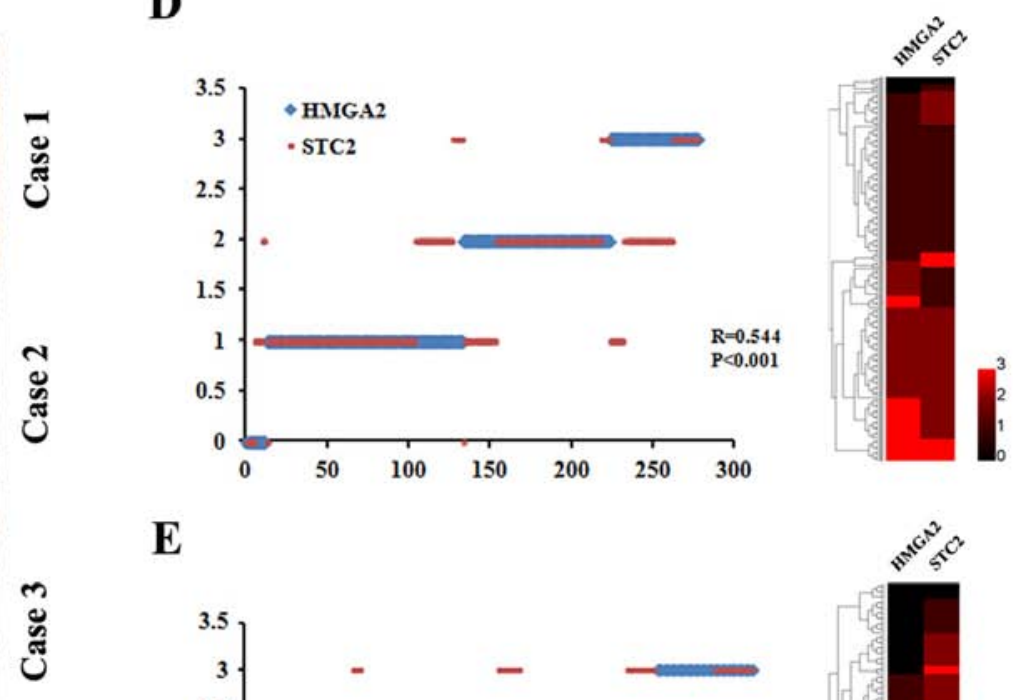

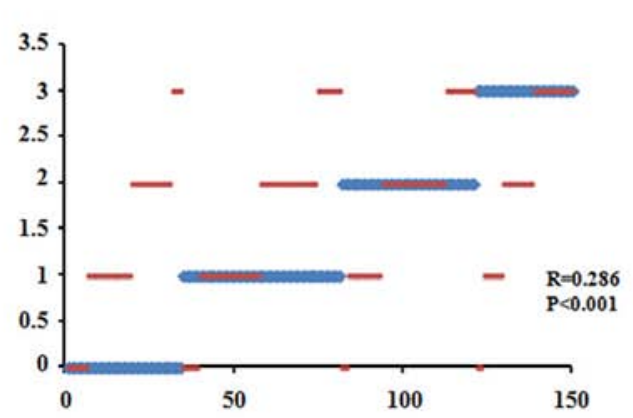

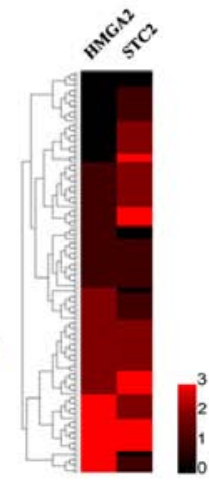

Figure 3. STC2 expression is transcriptionally regulated by HMGA2 and is positively correlated with the HMGA2 level in EOC. (A) Expression of $H M G A 2$ and STC2 was quantified by RT-PCR in 11 randomly selected HGSC. (B) 293T cells were transfected with reporter constructs containing various fragments of the STC2 promoter (right panel) along with $H M G A 2$ expression vector (pcDNA3.1-HMGA2) or empty vector (pcDNA3.1). Luciferase activity was measured $48 \mathrm{~h}$ after transfection and was normalized with Renilla activity. ${ }^{* *} \mathrm{P}<0.01$. (C) Photomicrographs show four examples of EOC cases with different immunointensity for HMGA2 (left panel) and STC2 (right panel). Correlation between HMGA2 and STC2 expression in (D) training and (E) validation cohort is shown in the dot plot and heatmap. STC2, stanniocalcin 2; HMGA2, high-mobility gene group A2; EOC, epithelial ovarian cancer; HGSC, high-grade serous cancer.

rate of HMGA2 was detected in serous tumors as compared with that in mucinous type in the training cohort $(58.6 \%$ in serous type, $26.8 \%$ in mucinous type, $\mathrm{P}<0.001$; Table III, Fig. 4A and $\mathrm{C}$ ) and validation cohort (54.6\% in serous type, $23.8 \%$ in mucinous type, $\mathrm{P}=0.001$; Table IV, Fig. $4 \mathrm{~A}$ and $\mathrm{C}$ ). A similar trend was observed in STC2 expression. A higher rate of STC2 was detected in serous tumors as compared with that in mucinous type in the training cohort $(59.5 \%$ in serous type, $26.8 \%$ in mucinous type, $\mathrm{P}<0.001$; Table III, Fig. 4B and D) and validation cohort $(64.8 \%$ in serous type, $42.9 \%$ in mucinous type, $\mathrm{P}=0.014$; Table IV, Fig. 4B and D). Statistical analysis revealed that HMGA2 and STC2 expression was not significantly associated with age, stage, or lymph node and distant metastatic status.

In 95 ovarian cancer cases with clinical follow-up data, we examined the correlation of STC2 expression with the overall survival using the Kaplan-Meier method. We found that the elevated expression of STC2 was associated with a shorter overall survival rate $(\mathrm{P}=0.016$, Fig. $4 \mathrm{E})$. These results indicated that $S T C 2$ may be a valuable predictive marker for prognosis in EOC, with a high STC2 expression being associated with a poor overall survival.

\section{Discussion}

In a previous gene profiling analysis, we showed the upregulation of STC2 expression in a transformed ovarian epithelial cell line that overexpressed HMGA2 (7). In the present study, we showed that STC2 and $H M G A 2$ were frequently co-upregulated in EOC. We also showed that STC2 was upregulated by $H M G A 2$ at the transcription level. Our findings in the present study suggest that $S T C 2$ is an immediate 
Table III. Association of HMGA2 and STC2 expression with clinicopathological characteristics in the training set ( $\mathrm{n}=278$ ).

\begin{tabular}{|c|c|c|c|c|c|c|c|}
\hline \multirow[b]{3}{*}{ Characteristics } & \multirow[b]{3}{*}{ Patients } & \multicolumn{3}{|c|}{ HMGA2 immunoreactivity } & \multicolumn{3}{|c|}{ STC2 immunoreactivity } \\
\hline & & \multicolumn{2}{|c|}{ No. of patients (\%) } & \multirow[b]{2}{*}{ P-value } & \multicolumn{2}{|c|}{ No. of patients (\%) } & \multirow[b]{2}{*}{ P-value } \\
\hline & & Low & High & & Low & High & \\
\hline \multicolumn{8}{|l|}{ Age (years) } \\
\hline$\leq 50$ & 160 & $72(45.0)$ & $88(55.0)$ & \multirow[t]{2}{*}{0.269} & 75 (46.9) & $85(53.1)$ & \multirow[t]{2}{*}{0.923} \\
\hline$>50$ & 118 & $61(51.7)$ & $57(48.3)$ & & $56(47.5)$ & $62(52.5)$ & \\
\hline \multicolumn{8}{|l|}{ T stage } \\
\hline $\mathrm{T} 1+\mathrm{T} 2$ & 233 & $108(46.4)$ & $125(53.6)$ & \multirow[t]{2}{*}{0.258} & $106(45.5)$ & $127(54.5)$ & \multirow[t]{2}{*}{0.216} \\
\hline $\mathrm{T} 3+\mathrm{T} 4$ & 45 & $25(55.6)$ & $20(44.4)$ & & $25(55.6)$ & $20(44.4)$ & \\
\hline \multicolumn{8}{|l|}{ Grading } \\
\hline Low & 75 & $49(65.3)$ & $26(34.7)$ & \multirow[t]{2}{*}{$<0.001$} & $53(70.7)$ & $22(29.3)$ & \multirow[t]{2}{*}{$<0.001$} \\
\hline High & 203 & $84(45.6)$ & $119(54.4)$ & & $78(43.0)$ & $125(57.0)$ & \\
\hline \multicolumn{8}{|l|}{ Node metastasis } \\
\hline Absent & 243 & $114(46.9)$ & $129(53.1)$ & \multirow[t]{2}{*}{0.414} & $111(45.7)$ & $132(54.3)$ & \multirow[t]{2}{*}{0.204} \\
\hline Present & 35 & $19(54.3)$ & $16(45.7)$ & & $20(57.1)$ & 15 (42.9) & \\
\hline \multicolumn{8}{|c|}{ Distant metastasis } \\
\hline Absent & 266 & $128(48.1)$ & $138(51.9)$ & \multirow[t]{2}{*}{0.662} & $124(46.6)$ & $142(53.4)$ & \multirow[t]{2}{*}{0.426} \\
\hline Present & 12 & $5(41.7)$ & $7(58.3)$ & & $7(58.3)$ & $5(41.7)$ & \\
\hline \multicolumn{8}{|l|}{ Histotype } \\
\hline Serous & 222 & $92(41.4)$ & $130(58.6)$ & \multirow[t]{2}{*}{$<0.001$} & $90(40.5)$ & $132(59.5)$ & \multirow[t]{2}{*}{$<0.001$} \\
\hline Mucinous & 56 & $41(73.2)$ & $15(26.8)$ & & $41(73.2)$ & $15(26.8)$ & \\
\hline
\end{tabular}

HMGA2, high-mobility gene group A2; STC2, stanniocalcin 2. Bold, statistically significant.
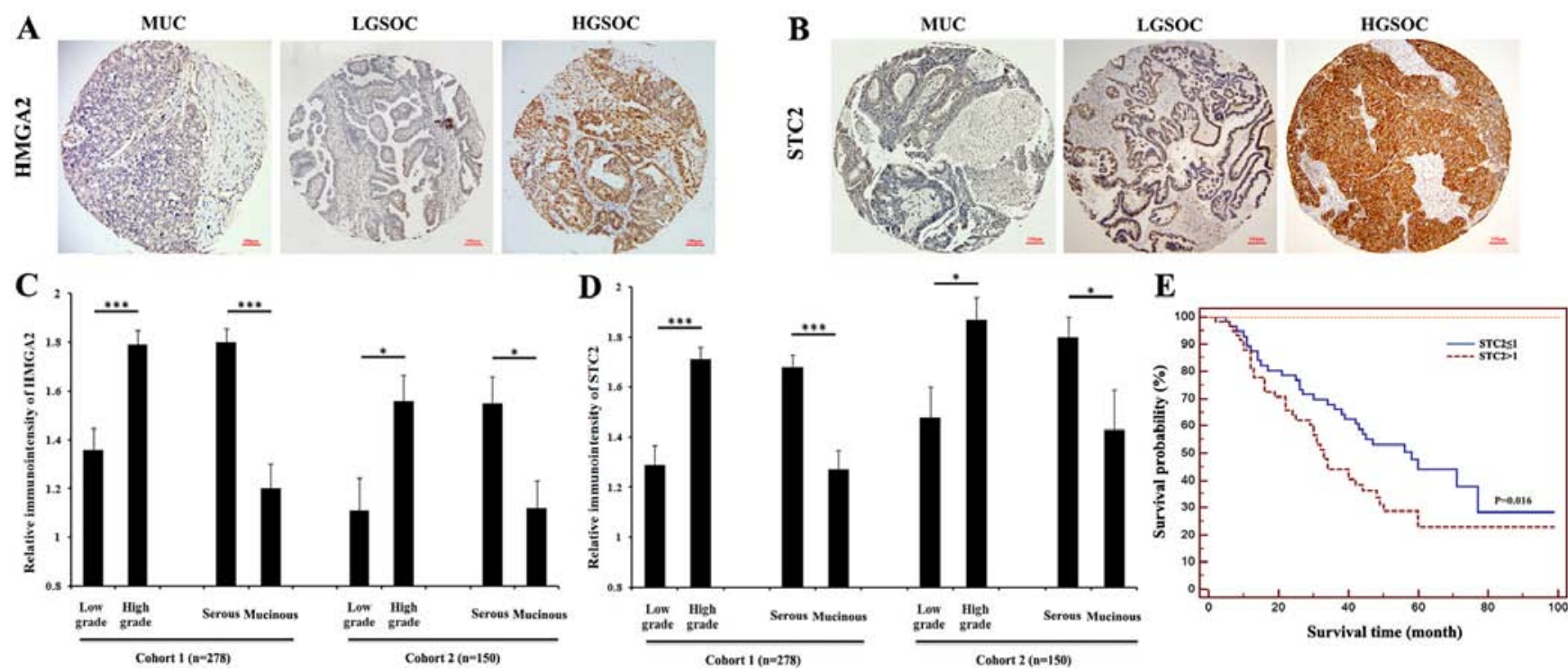

Figure 4. STC2 expression correlates with tumor grade, tumor histotype and correlates with a poor overall survival in EOC. Photomicrographs show some examples of immunoreactivity for (A) HMGA2 and (B) STC2 in mucinous (MUC), low-grade serous (LGSC) and high-grade serous carcinoma (HGSC). Histograms show the average immunoreactivity for (C) HMGA2 and (D) STC2 in association with tumor grade (left) and histotype (right) in the two cohorts. ${ }^{*} \mathrm{P}<0.05 ;{ }^{* * *} \mathrm{P}<0.001$. (E) Kaplan-Meier curves of STC2 expression and overall survival in 95 advanced ovarian cancer patients. STC2, stanniocalcin 2; EOC, epithelial ovarian cancer; HMGA2, high-mobility gene group A2.

downstream target of $H M G A 2$. STC2 overexpression was associated with aggressive ovarian cancer growth, high grade and poor clinical outcome.
STC2 was highly expressed in numerous solid human cancers and appeared to act as an oncoprotein. In breast cancer, STC2 was recognized as an estrogen-responsive gene 
Table IV. Association of HMGA2 and STC2 expression with clinicopathological characteristics in the validation cohort (n=150).

\begin{tabular}{|c|c|c|c|c|c|c|c|}
\hline \multirow[b]{3}{*}{ Characteristics } & \multirow[b]{3}{*}{ Patients } & \multicolumn{3}{|c|}{ HMGA2 immunoreactivity } & \multicolumn{3}{|c|}{ STC2 immunoreactivity } \\
\hline & & \multicolumn{2}{|c|}{ No. of patients (\%) } & \multirow[b]{2}{*}{ P-value } & \multicolumn{2}{|c|}{ No. of patients (\%) } & \multirow[b]{2}{*}{ P-value } \\
\hline & & Low & High & & Low & High & \\
\hline \multicolumn{8}{|l|}{ Age (years) } \\
\hline$\leq 50$ & 69 & $40(58.0)$ & $29(42.0)$ & 0.368 & $27(39.1)$ & $42(60.9)$ & 0.613 \\
\hline$>50$ & 81 & $41(50.6)$ & $40(49.4)$ & & $35(43.2)$ & $46(56.8)$ & \\
\hline \multicolumn{8}{|l|}{ T stage } \\
\hline $\mathrm{T} 1+\mathrm{T} 2$ & 124 & $70(56.5)$ & $54(43.5)$ & 0.188 & $52(41.9)$ & $72(58.1)$ & 0.744 \\
\hline $\mathrm{T} 3$ & 26 & $11(42.3)$ & $15(57.7)$ & & $10(38.5)$ & $16(61.5)$ & \\
\hline \multicolumn{8}{|l|}{ Grading } \\
\hline Low & 44 & $32(72.7)$ & $12(27.3)$ & 0.003 & $25(56.8)$ & $19(43.2)$ & 0.013 \\
\hline High & 106 & $49(46.2)$ & $57(53.8)$ & & $37(34.9)$ & $69(65.1)$ & \\
\hline \multicolumn{8}{|l|}{ Node metastasis } \\
\hline Absent & 143 & $79(55.2)$ & $64(44.8)$ & 0.167 & $59(41.3)$ & 84 (58.7) & 0.933 \\
\hline Present & 7 & $2(28.6)$ & $5(71.4)$ & & $3(42.9)$ & $4(57.1)$ & \\
\hline \multicolumn{8}{|c|}{ Distant metastasis } \\
\hline Absent & 135 & $76(56.3)$ & $59(43.7)$ & 0.090 & $55(40.7)$ & $80(59.3)$ & 0.658 \\
\hline Present & 15 & $5(33.3)$ & $10(66.7)$ & & $7(46.7)$ & $8(53.3)$ & \\
\hline \multicolumn{8}{|l|}{ Histotype } \\
\hline Serous & 108 & $49(45.4)$ & $59(54.6)$ & 0.001 & $38(35.2)$ & $70(64.8)$ & 0.014 \\
\hline Mucinous & 42 & $32(76.2)$ & $10(23.8)$ & & $24(57.1)$ & $18(42.9)$ & \\
\hline
\end{tabular}

HMGA2, high-mobility gene group A2; STC2, stanniocalcin 2. Bold, statistically significant.

and its expression was correlated with estrogen receptor (ER) status (22). In ovarian cancer, STC2 was identified as a biomarker and its overexpression was associated with a decreased disease-free interval (18). Findings of Law and Wong showed that two consecutive HRE binding sites in the STC2 promoter. STC2 was transactivated by HIF-1 (19). Consistent with a previous study (23), we showed that STC2 played an important role in cell migration and invasion in ovarian cancer cell lines. The results of the present study added another layer of evidence of HMGA2 as an oncogene in the tumorigenesis of EOC.

In gastric cancer, it was demonstrated that a high STC2 expression was correlated with an enhanced rate of venous invasion and became an independent prognostic marker $(24,25)$. In neuroblastoma, STC2 was highly expressed in stage 4 tumors (metastatic stage) and was recognized as a biomarker of metastatic neuroblastoma. STC2 was found to promote the invasion of neuroblastomas and erosion of blood vessels in vivo (26). Similarly, STC2 was shown to be upregulated and promoted cell proliferation and migration in hepatocellular carcinoma (27). In renal cell cancer, STC2 was used as an indicator for clinical prognosis (28). Furthermore, Ieta et al found that a higher level of STC2 expression was closely associated with larger tumor size, greater depth, increased lymph node metastasis, higher AJCC stage and worse survival (15). The abovementioned findings suggest that STC2 functioned as an oncogene in the course of tumor progression.
In summary, our results have shown that STC2 may be induced by HMGA2 at the transcription level. Additionally, HMGA 2 and STC2 were highly expressed in EOC. The stable overexpression of STC2 in T29 cells promoted migration and invasion in vitro, whereas its knockdown in Caov-3 inhibited cell migration and invasion in vitro. Patients with serous histotype and poorer differentiation grade had higher rates of HMGA2 and STC2 high intensity. The EMT-enhancing properties of HMGA2 in EOC appeared to be partly mediated by STC2. We also found that STC2 may be used as an independent predictor of survival for EOC patients. Immunohistochemistry for STC2 proved a clean and reliable stain and may serve as a tumor prognostic marker for HGSC. Further characterization of STC2-mediated tumorigenesis in HGSC may be useful to develop potential therapeutic modality targeting STC2 for the aggressiveness of HGSC.

\section{Acknowledgements}

We would like to thank the staff at the Pathology Core Laboratory for technical support. The present study was supported in part by the Marsha Rivkin Ovarian Cancer Research Award, the Dixon Translation fund, the National Natural Science Foundation of China (nos. 81302073, 81302072 and 81172313), the Zhejiang Provincial Natural Science Foundation of China (LQ13H160011), and the Fundamental Research Funds for the Central Universities (2014QNA7018). 


\section{References}

1. Siegel R, Ma J, Zou Z and Jemal A: Cancer statistics, 2014. CA Cancer J Clin 64: 9-29, 2014.

2. Coleman RL, Monk BJ, Sood AK and Herzog TJ: Latest research and treatment of advanced-stage epithelial ovarian cancer. Nat Rev Clin Oncol 10: 211-224, 2013.

3. Kurman RJ and Shih IeM: The origin and pathogenesis of epithelial ovarian cancer: A proposed unifying theory. Am J Surg Pathol 34: 433-443, 2010.

4. Park SM, Shell S, Radjabi AR, Schickel R, Feig C, Boyerinas B, Dinulescu DM, Lengyel E and Peter ME: Let-7 prevents early cancer progression by suppressing expression of the embryonic gene HMGA2. Cell Cycle 6: 2585-2590, 2007.

5. Welsh JB, Zarrinkar PP, Sapinoso LM, Kern SG, Behling CA, Monk BJ, Lockhart DJ, Burger RA and Hampton GM: Analysis of gene expression profiles in normal and neoplastic ovarian tissue samples identifies candidate molecular markers of epithelial ovarian cancer. Proc Natl Acad Sci USA 98: 11761181,2001

6. Wei JJ, Wu J, Luan C, Yeldandi A, Lee P, Keh P and Liu J: HMGA2: A potential biomarker complement to P53 for detection of early-stage high-grade papillary serous carcinoma in fallopian tubes. Am J Surg Pathol 34: 18-26, 2010.

7. Wu J, Liu Z, Shao C, Gong Y, Hernando E, Lee P, Narita M, Muller W, Liu J and Wei JJ: HMGA2 overexpression-induced ovarian surface epithelial transformation is mediated through regulation of EMT genes. Cancer Res 71: 349-359, 2011.

8. Malek A, Bakhidze E, Noske A, Sers C, Aigner A, Schäfer R and Tchernitsa $\mathrm{O}: H M G A 2$ gene is a promising target for ovarian cancer silencing therapy. Int J Cancer 123: 348-356, 2008.

9. Wu J and Wei JJ: HMGA2 and high-grade serous ovarian carcinoma. J Mol Med Berl 91: 1155-1165, 2013.

10. Morishita A,Zaidi MR, Mitoro A, Sankarasharma D, Szabolcs M, Okada Y, D'Armiento J and Chada K: HMGA2 is a driver of tumor metastasis. Cancer Res 73: 4289-4299, 2013.

11. Zha L, Zhang J, Tang W, Zhang N, He M, Guo Y and Wang Z: HMGA 2 elicits EMT by activating the Wnt/ $\beta$-catenin pathway in gastric cancer. Dig Dis Sci 58: 724-733, 2013.

12. Serlachius M, Alitalo R, Olsen HS and Andersson LC: Expression of stanniocalcin-1 in megakaryocytes and platelets. Br J Haematol 119: 359-363, 2002.

13. Chang AC and Reddel RR: Identification of a second stanniocalcin cDNA in mouse and human: Stanniocalcin 2. Mol Cell Endocrinol 141: 95-99, 1998.

14. Liu G, Yang G, Chang B, Mercado-Uribe I, Huang M, Zheng J, Bast RC, Lin SH and Liu J: Stanniocalcin 1 and ovarian tumorigenesis. J Natl Cancer Inst 102: 812-827, 2010.

15. Ieta K, Tanaka F, Yokobori T, Kita Y, Haraguchi N, Mimori K, Kato H, Asao T, Inoue H, Kuwano H, et al: Clinicopathological significance of stanniocalcin 2 gene expression in colorectal cancer. Int J Cancer 125: 926-931, 2009.
16. Girgis AH, Iakovlev VV, Beheshti B, Bayani J, Squire JA, Bui A, Mankaruos M, Youssef Y, Khalil B, Khella H, et al: Multilevel whole-genome analysis reveals candidate biomarkers in clear cell renal cell carcinoma. Cancer Res 72: 5273-5284, 2012.

17. Yuan Y, Yang ZL, Zou Q, Li JH, Li DQ, Liang LF, Zeng GX and Chen SL: Comparative study of clinicopathological significance, BIRC7, and STC2 expression between squamous cell/adenosquamous carcinomas and adenocarcinoma of gallbladder. Neoplasma 60: 698-705, 2013.

18. Buckanovich RJ, Sasaroli D, O'Brien-Jenkins A, Botbyl J, Hammond R, Katsaros D, Sandaltzopoulos R, Liotta LA, Gimotty PA and Coukos G: Tumor vascular proteins as biomarkers in ovarian cancer. J Clin Oncol 25: 852-861, 2007.

19. Law AY and Wong CK: Stanniocalcin-2 is a HIF-1 target gene that promotes cell proliferation in hypoxia. Exp Cell Res 316: 466-476, 2010

20. McMillen BD, Aponte MM, Liu Z, Helenowski IB, Scholtens DM, Buttin BM and Wei JJ: Expression analysis of MIR182 and its associated target genes in advanced ovarian carcinoma. Mod Pathol 25: 1644-1653, 2012.

21. Cui T and Leng F: Specific recognition of AT-rich DNA sequences by the mammalian high mobility group protein AT-hook 2: A SELEX study. Biochemistry 46: 13059-13066, 2007.

22. Bouras T, Southey MC, Chang AC, Reddel RR, Willhite D, Glynne R, Henderson MA, Armes JE and Venter DJ: Stanniocalcin 2 is an estrogen-responsive gene coexpressed with the estrogen receptor in human breast cancer. Cancer Res 62: 1289-1295, 2002.

23. Law AY and Wong CK: Stanniocalcin-2 promotes epithelialmesenchymal transition and invasiveness in hypoxic human ovarian cancer cells. Exp Cell Res 316: 3425-3434, 2010.

24. Yokobori T, Mimori K, Ishii H, Iwatsuki M, Tanaka F, Kamohara Y, Ieta K, Kita Y, Doki Y, Kuwano H, et al: Clinical significance of stanniocalcin 2 as a prognostic marker in gastric cancer. Ann Surg Oncol 17: 2601-2607, 2010.

25. Wang YY, Li L, Zhao ZS and Wang HJ: Clinical utility of measuring expression levels of KAP1, TIMPI and STC2 in peripheral blood of patients with gastric cancer. World J Surg Oncol 11: 81, 2013

26. Volland S, Kugler W, Schweigerer L, Wilting J and Becker J: Stanniocalcin 2 promotes invasion and is associated with metastatic stages in neuroblastoma. Int J Cancer 125: 2049-2057, 2009.

27. Wang H, Wu K, Sun Y, Li Y, Wu M, Qiao Q, Wei Y, Han ZG and Cai B: STC2 is upregulated in hepatocellular carcinoma and promotes cell proliferation and migration in vitro. BMB Rep 45: 629-634, 2012.

28. Dondeti VR, Wubbenhorst B, Lal P, Gordan JD, D'Andrea K, Attiyeh EF, Simon MC and Nathanson KL: Integrative genomic analyses of sporadic clear cell renal cell carcinoma define disease subtypes and potential new therapeutic targets. Cancer Res 72: 112-121, 2012. 